\title{
PENSAR PROBLEMÁTICAMENTE: UNA TENTATIVA DE INTERPRETACIÓN GLOBAL DE LA OBRA DE DELEUZE
}

\author{
Thinking PRoblematically: A TENTATIVE General \\ INTERPRETATION OF DELEUZE'S WORK
}

\author{
Julien Canavera
}

\begin{abstract}
RESUMEN
En el presente artículo nos proponemos realizar una lectura transversal de Deleuze donde se sostiene que la vocación bélica de la filosofía — la de arremeter contra la lógica del reconocimiento y sus dos correlatos, la estupidez y el gregarismo- es inseparable de una redefinición del filosofar como actividad de pensarproblemáticamente, cuya lógica — la del sentido producido y de la sensación constituyente — implica una nueva relación al tiempo donde el futuro inanticipable — que hace trizas el horizonte de presencia y coherencia relativa en el cual opera la lógica del reconocimient- tiene el primado.
\end{abstract}

PALABRAS CLAVE: Deleuze, reconocimiento, problematización, experimentalismo, tiempo.

\section{ABSTRACT}

In this article we propose a transversal reading of Deleuze in which it is sustained that the warlike vocation of philosophy -the assaults on the logic of recognition and its two correlates, stupidity and gregarism-is inseparable from a redefinition of philosophising as an exercise in problematization, whose logic -that of produced sense and constitutive sensation-implies a new relationship with time, where the unforeseeable future -which tears to shreds the presence horizon and relative coherence in which the logic of recognition operates- takes precedence.

KEYWORDS: Deleuze, recognition, problematization, experimentalism, time. 


\section{INTRODUCCIÓN}

«Históricamente [dice Deleuze] se ha constituido una imagen del pensamiento llamada filosofía que impide que las personas piensen» $(D, 17)^{1}$. Esa Imagen — que nuestro autor escribe en ocasiones con una «i» mayúscula, con tal de remarcar que no se trata «de tal o cual imagen del pensamiento, variable según los filósofos, sino de una sola Imagen en general que constituye el presupuesto subjetivo de la filosofía en su conjunto» (DR, 205) - se caracteriza ante todo por asimilar la actividad de pensar a una búsqueda natural y desinteresada de la verdad, como bien testimonia la tradición filosófica desde Aristóteles («todos los hombres tienen naturalmente el deseo de saber») hasta Descartes («el buen sentido es la cosa mejor repartida del mundo») y más allá.

\section{LA CRÍTICA DE LA IMAGEN DOGMÁTICA: MODELO GENERAL DEL RECONOCIMIENTO Y CULTO A LA INTERIORIDAD}

El primer punto que retiene, pues, la atención de Deleuze es que, implícita o explícitamente, siempre se presupone, «bajo el doble aspecto de una buena voluntad del pensador y de una recta naturaleza del pensamiento» (DR, 204) ${ }^{2}$, una suerte de afinidad mutua o de co-pertenencia del pensamiento y de la verdad, expresada ora en la «connaturalidad de la idea», ora en el «a priori de los conceptos» (NF, 146), en virtud de la cual se nos dice que «el pensamiento posee formalmente lo verdadero y quiere materialmente lo verdadero» (DR, 204), no designando lo verdadero, por su parte, otra cosa que no sea el justo contenido correspondiente a lo que debe ser racionalmente dicho y/o pensado. Lo que de ello se sigue —y aquí es donde despunta, a ojos de nuestro autor, la primera implicación de semejante imagen — es la inscripción del pensamiento, por naturaleza — lo veremos— polimórfico, «en la máquina lógica [y homogeneizadora] de lo que conviene llamar "lo racional"» (Villani, 2013, p. 31); vale decir, en la categoría de representación como «forma emblemática de la razón». Así, pues, la consecuencia que se desprende inmediatamente de esta sumisión compelida del pensamiento a la razón representativa, de cuyo imperium la pretendida posesión formal de la verdad constituye la piedra angular, no es sino la definición tradicional del pensar como conocer. Ahora bien, habida cuenta de que la razón

\footnotetext{
${ }^{1}$ Para las abreviaturas, véase la bibliografía.

${ }^{2}$ Por lo que se refiere a las obras de Deleuze y las abreviaturas usadas, véase el listado en la bibliografía.
} 
representativa se define por prejuzgar la forma de lo que está por pensar, no es de extrañar que todo conocer, a su vez, sea ya siempre un reconocer. Pero, ¿en qué consiste concretamente el reconocimiento? Designa el movimiento («falso y abstracto», diría Deleuze) mediante el cual el pensar representativo, para quien la estabilidad y la permanencia son indicios de la realidad de una cosa, procede, en la aprehensión de tal o cual fenómeno, a ahorrarse y por ende a eliminar toda consideración superflua acerca de las contingencias y de las múltiples diferencias accidentales, en provecho de las grandes semejanzas — vale decir: de todo aquello que pueda tornarse objeto de un conocimiento estable-, y que, a este fin, echa mano de ambas operaciones solidarias de la mente que son la abstracción y la generalización. Pues bien, así como «una hoja no es igual a otra», asimismo «el concepto hoja se ha formado al abandonar de manera arbitraria esas diferencias individuales, al olvidar las notas distintivas, con lo cual se suscita entonces la representación, como si en la naturaleza hubiese algo separado de las hojas que fuese la "hoja"» (Nietzsche, 1996, pp. 23-24). En pocas palabras, diríase pues que el acto de reconocer o de representar, sea como fuere su complejidad según los casos, siempre acaba retrotrayendo lo desconocido a lo conocido, lo anormal a lo normal, lo nuevo a lo antiguo — y, en suma, lo diferente a lo idéntico- . «El prefijo RE en la palabra representación [resume lapidariamente Deleuze] significa esa forma conceptual de lo idéntico que subordina a las diferencias» (DR, 101). Pensar la diferencia, no «en cuanto diferencia» (Heidegger, p. 109), sino en función de su grado de conveniencia a la norma de identidad (el concepto en general): ésa es, pues, la esencia de la representación, ya se trate de la percepción de un objeto presente, de la memoria de un objeto pasado o de la imaginación de un objeto futuro.

Ahora bien - $-\mathrm{y}$ aquí es donde se perfila la segunda implicación de la imagen dogmática一, si tenemos en cuenta con Nietzsche que «modos de pensamiento» y «maneras de vivir» están íntima e estrechamente ligados en una «unidad compleja» a raíz de la cual «un paso para la vida» implica necesariamente «un paso para el pensamiento» y viceversa $(N, 24)$, entonces divisamos que aquello que, en última instancia, se expresa en la definición —y el ejercicio- del pensar como representar o reconocer no es sino la «exigencia sedentaria de una vida condenada a reproducir las condiciones restrictivas de la supervivencia» (Martin, p. 138). El reconocimiento, en pocas palabras, se presenta como el correlato espiritual de unas «tareas [ante todo práxico-vitales] de conservación, de adaptación y de utilidad» $(N F, 61)$. Pues si, como Bergson, tenemos presente, por un lado, que la mayor parte del tiempo «es para actuar que pensamos» (1962, p. 296) —lo cual se podría 
traducir diciendo que nuestra percepción, lejos de poder concebirse como un mero órgano de conocimiento sin otra finalidad que el saber, «es siempre sensoriomotriz y pragmática, siempre orientada por y hacia las necesidades y los intereses de la vida» (Marrati, p. 269)—; y, por la otra, que nuestra acción sobre lo real está sometida a la exigencia de utilidad y de eficacia necesaria para la conducta regular de nuestra vida en sociedad, entonces «no es de extrañar que los hábitos [esencialmente reactivos] de la acción destiñan sobre los de la representación, y que nuestro espíritu siempre perciba las cosas en el orden mismo en el que tenemos costumbre de figurárnoslas cuando nos proponemos actuar sobre ellas» (Bergson, 1962, p. 296). No retener de una cosa nada más que aquello que pueda dar lugar a un conocimiento estable y/o a un principio de entendimiento mutuo: en esto consiste, pues, nuestra percepción o representación corriente de la realidad, en cuanto sometida al imperativo — «humano, demasiado humano»— de acudir directamente a lo esencial.

En esas condiciones, no es de sorprender que la verdad a su vez se presente ante todo en la forma de un «tratado de paz»; vale decir, de una convención lingüística y conceptual por la que «se fija lo que a partir de entonces ha de ser "verdad"» (Nietzsche, Id., p. 20) —-tesis que Deleuze, sin decirlo expresamente, considera como adquirida-. Por ello, diríase que la búsqueda de la verdad a toda costa no responde tanto al cometido propiamente epistemológico de conocer la estructura radical — si la hay- de lo real, cuanto a la necesidad de «tener la garantía, la seguridad de que [se puede] disponer en cualquier momento de una forma de decidir si algo es verdad» (Rodríguez, p. 151); e, inversamente, de poder descalificar, no sólo como falso, sino también como mentira, todo aquello que haga peligrar el control del hombre sobre (el mundo de) la vida. He aquí, de hecho, la autocentración, la negatividad esencial de la razón en Occidente: la cuestión es «no hacer cualquier cosa, no decir disparates, acatar las leyes, las reglas, las técnicas en vigor, en una común exclusión de las partes animales, vegetales, minerales; en pocas palabras, de la metamorfosis» (Villani, 2003, pp. 204-205). Si en consecuencia divisamos que siempre y por todas partes el Logos y un cierto Nomos permanecen ligados, es porque la verdad, entendida — dice Nietzsche- como «voluntad de verdad», no localiza sino su origen en la moral. En efecto, ¿quién sino la moral puede «[hacer] de la vida algo que debe ser juzgado, medido, limitado, y del pensamiento, una medida, un límite, que se ejerce en nombre de los valores superiores —lo Divino, lo Verdadero, lo Bello, el Bien...»? (N, 28)—. ¿Qué otra cosa que no sea la moral puede comunicar al pensamiento esa tendencia reactiva a reterritorializarse mezquina y celosamente sobre un pequeño islote de conocimientos firmes 
y seguros, y a la verdad, esa función pacificadora de imponer unos puntos de anclaje, una «segmentariedad dura», una «distribución fija y sedentaria» a una realidad, por definición, profundamente procesual, relacional y moviente?

Así, pues, no hay nada sorprendente - lo veníamos explicando- en afirmar que la verdad nunca oficiaría como tratado de paz; vale decir, que jamás cargaría con semejante fardo moral, si no fuera porque la moral a su vez constituye la expresión reactiva de un cierto miedo a la vida. Miedo a una vida profundamente polemológica, exuberante y proteiforme que «tiende [como dice Nietzsche] a confundir, a engañar, a disimular, a deslumbrar, a cegar» (apud NF, 136). Del mismo modo que es cierto que la búsqueda de la verdad a toda costa testimonia el miedo de los hombres, no tanto - lo decíamos líneas atrás - a ser engañados, como a «ser perjudicados mediante el engaño» (Nietzsche, Id., p. 21) y otra clase de embustes fomentados por la vida, en cuanto «potencia de lo falso» o «potencia que hace indecidible lo verdadero» $(C, 106)$, también es cierto que el mayor de los temores atañe, en última instancia, a la caída y al hundimiento en «el abismo indiferenciado», en «la nada negra» (DR, 61). De ahí — como bien señala Deleuze- la falsa alternativa que, de Platón a Hegel pasando por Kant, rige la tradición filosófica y cuya fórmula rezaría así: «podéis escoger entre la trascendencia y el caos...» $(Q F, 55)$. «O bien un fondo indiferenciado [...] un abismo sin diferencias ni propiedades, o bien un Ser soberanamente individuado, una Forma fuertemente personalizada. Fuera de este Ser o de esta Forma, sólo tenemos el caos...» $(L S, 140)$.

Llegado este punto, es preciso señalar que no hay miedo a la vida - y por ende temor a ser engullido por el sin-fondo o el no-ser informe- que no implique a su vez cierta voluntad de dominio, en el sentido de que el hombre, por lo general, sólo necesita domeñar aquello que escapa a su control y a su capacidad previsora. $\mathrm{Si}$ «el pensar de los filósofos [escribe Nietzsche] no es tanto un descubrir cuanto un reconocer, un encontrar de nuevo, un volver atrás» (Nietzsche, 2008, p. 44), es precisamente porque se indexa sobre — y satisface — dicha necesidad de control o de dominio, al «hacer que algo extraño se convierta en algo conocido», siendo lo conocido «aquello a lo que estamos lo suficientemente habituados como para no asombrarnos [...] todo lo que nos es familiar» (Nietzsche, 2007, pp. 213-214). De este acoplamiento «miedo a la vida/voluntad de dominio» es de donde surge - y se impone, finalmente, para el pensamiento reducido a razón— la imperiosa necesidad de postular la existencia salvífica de un trasmundo. Henos aquí, dice Deleuze, con el «regalo envenenado del platonismo», el que «consiste [...] en haber otorgado a la trascendencia un sentido filosófico plausible (triunfo del juicio de Dios)» ( $C C$, 190). ¿En qué sentido? La trascendencia, independientemente de los nombres que 
históricamente haya conocido (Ser, Dios, Sujeto), «implica siempre una dimensión suplementaria a las dimensiones de lo dado» (SFP, 156), desempeñando así un papel eminentemente fundacional. En efecto, ¿a quién sino al fundamento, en cuanto detención del movimiento y operación de cierre-bloqueo, puede corresponder el cometido de operar como punto-fuerte (o arquimédico), a raíz del cual se despliega y se estructura de forma arborescente un "sistema cerrado» en el interior del cual el pensamiento, pudiendo proceder a un reparto fijo, sedentario y jerárquico de los conceptos y los seres, se halla asimismo en condiciones de recobrar la tan anhelada paz intelectual? Dicho en otros términos, cuando el imperativo de «orientarse en el pensamiento» (como diría Kant) sucumbe, ante el torbellino de la vida, a la presión de las fuerzas reactivas (= fuerzas de representación o de conciencia), no es sino al fundamento a quien el pensamiento se encomienda, no teniendo esta práctica del «radicalismo del punto de partida» (Husserl, p. 25) otro cometido que el de garantizar la posibilidad de «reportar todas las formas visibles sobre los ejes de un plano, dividir el espacio visible en un juego de plazas para inscribir todos los datos sobre una superficie que respeta sus relaciones» (Martin, p. 259).

El espacio que describe entonces el «pensamiento de la trascendencia» el cual, según Deleuze, es co-sustancial a la «filosofía de la representación» por cuanto la representación constituye «el lugar de [esa] ilusión trascendental» (DR, 394), de ese «mal metafísico» por antonomasia (Villani, 1999, p. 48), que es la trascendencia - se confunde en última instancia con una suerte de «islote» bien delimitado y ordenado de objetos reconocidos y/o de significaciones explícitas. Henos aquí, según una fórmula de la Crítica de la razón pura, con el «país del entendimiento puro» (Kant, p. 445) cuya característica primera, con tal de consagrar e imponer la experiencia pacificada de los fenómenos mejor conocidos, estriba en mantenerse a salvo del «océano tempestuoso» de materia intensa que lo rodea; vale decir, a cubierto de todo aquello que, no siendo codificable bajo la forma de elementos de percepción reconocibles, está ya siempre amenazando de puesta en jaque al mecanismo de reconocimiento: «si el cinabrio fuese ora rojo, ora negro, ora ligero, ora pesado...» (apud FCK, 29). Promoción de los reencuentros plácidos, consagración de los actos rutinarios de reconocimiento: ésa es, indudablemente, una manera eficaz de no «enseñar al hombre a vivir en lo desconocido» (Chestov, p. 208). Pues ni qué decir tiene que el pensar como reconocer «es un juego que sólo funciona si previamente se coloca del lado del no-ser - lo que no es sensible ni inteligible - todo aquello que no pasa por la red conceptual de la representación» (Pardo, p. 33); vale decir, todo aquello — se le llame diferencia, simulacro, devenir o intensidad - que no viene intrínsecamente referido a la verticalidad de un Uno y 
Mismo trascendente, a imagen de la «buena copia» platónica que siempre conserva una «relación interior espiritual, nosológica y ontológica» con el modelo o Idea (DR, 392-393). Así, pues, quedan manifiestas las coordenadas ontológicas y epistemológicas dentro de las que opera la razón o el pensar representativo: ser significa ser lo mismo; y pensar, reducir sistemáticamente a lo mismo.

Si la definición, así como la puesta en práctica, del pensar como reconocer resulta entonces problemática, diríase, hablando con propiedad, que lo es doblemente: lo es ante todo a nivel especulativo. ¿En qué sentido? Pues, cuando el pensamiento permanece atrapado en la telaraña del reconocimiento, cuya forma «nunca santificó otra cosa que lo reconocible y lo reconocido», ni «inspiró otra cosa que conformidades» (DR, 209), se ve inexorablemente abocado a no producir más que «discursos imbéciles construidos totalmente a base de verdades», pero de verdades que «son las de un alma baja, pesada y de plomo» (NF, 149). Por otra parte, la ecuación «pensar $=$ reconocer» resulta también $-\mathrm{y}$, quizá, todavía más- problemática a nivel práctico. ¿Por qué? Porque si bien el reconocimiento continúa siendo «insignificante como modelo especulativo»: designa «la banalidad cotidiana en persona» (DR, 209), la forma de pensar «que llega menos lejos, la más pobre y la más pueril» $(Q F, 140)$, cuando no, el punto cardinal a raíz del cual el discurso filosófico hace círculo con la doxa y, «elevándola al nivel racional», no puede entonces contemplar otra alternativa que no sea la de reencontrar las ideas de la época «bendiciéndolas con el signo de la filosofía» (DR, 208-209); resta que cesa inmediatamente de serlo una vez que se tienen en cuenta los fines prácticos a los que sirve. «El reconocimiento [dice Deleuze] encuentra su finalidad práctica en los "valores establecidos"» (DR, 210). Y esto es así porque lo reconocido es, no sólo la cosa (objeto, persona, lugar, materia, etc.), sino también los valores que versan sobre dicha cosa.

Llegado este punto, Deleuze puede entonces levantar acta de la «inquietante complacencia» que la imagen dogmática, en cuanto consagración del reconocimiento como modelo del pensar, testimonia hacia el Orden vigente y los poderes fácticos que garantizan su perennidad. El filósofo (el «obrero de la filosofía», diría Nietzsche) «se declara sometido a las exigencias de la verdad, de la razón; pero tras las exigencias de la razón se reconocen con frecuencia fuerzas que no son tan razonables, Estados, religiones, valores vigentes» ( $N, 27-28)$. En este sentido, diríase que la lógica del reconocimiento realiza plenamente —como, de modo ejemplar, testimonia el hegelianismo - el deseo gregario de las fuerzas que en su origen la animan: se trata de «conservar (incluso y, quizás, ante todo, precisa Deleuze, en sentido moral y político)»(Zourabichvili, 2004, p. 55). Si 
nuestro autor considera entonces que «los filósofos a menudo sólo hacen falsas críticas», es porque se contentan, bajo el manto del desinterés, con «[defender] el orden, las autoridades, las instituciones, las buenas costumbres, todo aquello en lo que cree el hombre corriente» (Descombes, p. 201). Pues, cuando la filosofía —a imagen de Kant y de su «tribunal de paz»— empieza por «creer en lo que critica» (NF, 128), no acaba sino confundiendo «la positividad de una crítica con un humilde reconocimiento de los derechos de lo criticado» (NF, 127), convirtiendo así la crítica total en una "política de compromiso» (NF, 127). Por ello, siempre conviene recordar esta extraña declaración de Leibniz que aún pesa sobre la filosofía: «producir nuevas verdades, pero sobre todo "sin invertir los sentimientos establecidos"» (NF, 147).

Contra la complacencia hacia la doxa y el sentido común, que desemboca en «un pensamiento [imbécil] que no perjudica a nadie» $(D R, 210)$; pero también contra la connivencia con el Orden establecido, que hace de la vida (o «voluntad de poder», como diría Nietzsche) «una voluntad de hacerse atribuir los valores en curso en una sociedad dada (dinero, honores, poder, reputación)» (NF, 116), y de la filosofía, el simple «recuento de todas las razones que el hombre se aplica para obedecer» $(N, 27)$. En pocas palabras, contra la estupidez (o impoder para problematizar) y el gregarismo (o incapacidad para experimentar), facetas respectivamente especulativa y práctica del reconocimiento, el propósito de Deleuze no es otro que impugnar y destruir la imagen «dogmática», «ortodoxa» e incluso «moral» del pensamiento que sirve de piedra angular al modelo general del reconocimiento. Ahora bien, ¿'en provecho de qué impugna (o acabará impugnando) Deleuze la Imagen del pensamiento? En beneficio, dicho sumariamente, de una «nueva imagen del pensamiento sin imagen» (Zourabichvili, Id., p. 64), para la cual «el pensamiento es creación, y no voluntad de verdad» $(Q F, 57)$, así como de un nuevo ejercicio del pensamiento, donde pensar designa el «ejercicio peligroso» de «pensar problemáticamente» (Foucault, p. 33; Canavera, 2015), y ya no el tibio y moderado movimiento de reconocer o de representar. De ahí, sea dicho de una vez, que la figura consensual y reconciliadora del «obrero de la filosofía», en sentido nietzscheano (apud NF, 8), deje asimismo paso a la figura bélica del «filósofo guerrero», para quien «la filosofía sirve para entristecer» $\mathrm{y}$ «denunciar la bajeza» (NF, 149).

\section{El PENSAMIENTO Y SU AFUERA: VIDA, PROBLEMA, DIFERENCIA}

Sentado esto, ¿qué es lo primero que implica esta nueva imagen? Implica ante todo una operación à la lettre heterodoxa cuyos dos momentos solidarios son: $1 /$ acabar con el «principio constitutivo» de la imagen dogmática: el «culto a la 
interioridad»; 2/ hacer «lo que, literalmente, nunca han hecho los filósofos», a saber: «conectar el pensamiento con el exterior» (ID, 325), enchufarlo sobre el Afuera (entiéndase: la vida) cuyo concepto — que Deleuze escribe a veces con una «a» mayúscula, con tal de remarcar su irreductibilidad a la exterioridad meramente relativa y actual de los datos sensoriales - debe entenderse, como bien muestra Zourabichvili (Id., p. 49), en dos sentidos complementarios: 1/ lo no-representable, o el afuera de la representación; 2/ la consistencia misma de lo no-representable; es decir, la exterioridad de las relaciones, el campo informal de las relaciones, al que Deleuze llama plano de inmanencia, y que la representación «no puede presentar» (ES, 22). Así, pues, la cuestión — para Deleuze — estriba en transmutar el círculo vicioso de «un conocimiento [que] se opone a la vida, pero porque expresa una vida que contradice la vida, una vida reactiva» (NF, 141), en el círculo virtuoso de una vida que «activa el pensamiento»y de un pensamiento que «a su vez afirma la vida» ( $N$, 24). De ello se desprende, pues, la declaración programática de Deleuze: «ya no haremos comparecer la vida ante las categorías [ideales] del pensamiento» (los ya mencionados valores superiores), «arrojaremos el pensamiento en las categorías [materiales] de la vida» (IT-C2, 251).

Para comprender el sentido y el alcance de semejante inversión, hace falta primero interrogar la noción deleuziana de «vida» (cfr. Canavera, 2016). ¿Qué entiende, pues, Deleuze por vida? Ajena a todo tipo de mecanicismo y de finalismo cuyo «error común» es creer que el todo de lo real está dado por anticipado $(B, 110)$, como a cualquier forma de espontaneísmo cuyo error es creer que la actividad innovadora puede independizarse a voluntad de las condiciones objetivas de existencia y sobrevivir a ellas $(A E, 34)$, se dirá ante todo de la vida que designa la naturaleza en tanto que naturaleza productiva. Luego que la vida como naturaleza productiva - $\mathrm{O}$, lo que es igual, la naturaleza como potencia vital - remite al proceso de producción que describe, a la vez que lo construye, el único plano de realidad existente donde productor y producto (entiéndase: la vida como Natura naturans y lo viviente como Natura naturata) se entrelazan y relanzan mutuamente en los lazos de una común inmanencia, conforme al modelo de una causalidad próxima o eficiente donde «la causa permanece en sí para producir» $\mathrm{y}$ «el efecto o el producto permanece en la causa» (SFP, 108). Así es cómo se configura —en un «movimiento de dos movimientos» (Badiou, pp. 63-64) — «un Todo sin cierre» (Althusser, p. 81), una totalidad abierta, «al lado» y siempre en devenir ( $A E, 47)$, cuyas partes, producciones o elementos se comunican transversal y rizomáticamente más acá de los reinos (minerales, vegetales, animales, humanos) establecidos, de suerte que «lo 
[primero] que existe [en el orden de lo real] es animal-vegetal, vegetal-humano, mujer-mineral, hombre-molécula» (Villani, 1999, p. 19).

La vida, en la medida en que no se agota - lo hemos visto- en un simple espontaneísmo, no constituye pues un principio «productor de realidad» ( $A E$, 33) sin señalar a su vez un "principio esencialmente plástico», en el sentido de que «se determina en cada caso con lo que determina» (NF, 74). Pero, que designe un principio no más ancho que aquello que viene a condicionar (= lo viviente) no significa, empero, que la vida se deje definir por la organización, ni tampoco que se deje circunscribir en los límites de lo viviente cuyos «tres estratos más notables a nuestra escala son los estratos materiales, orgánicos y psíquicos» (Sauvagnargues, 2004, p. 139). Por esta razón —y según un leitmotiv deleuziano— se dirá de la vida que no designa lo que está fuera de lo viviente, sino el «afuera no-exterion» ( $Q F$, 62) que insiste o persiste virtual y problemáticamente en lo viviente; y de lo viviente, que es lo que existe bic et nunc, aquí y ahora, como un proceso de actualización o de resolución local de esa (pura) virtualidad que es la vida. Y si, sea dicho de una vez, se habla aquí de lo viviente como el resultado de un «proceso de actualización de un virtual», y no como el resultado de un «proceso de realización de un posible», es porque el estado de «différentiation» (con una «t»), propio de esta pura virtualidad que es la vida, se caracteriza ante todo por excluir a lo idéntico como condición previa, impidiendo semejante exclusión que el actual al que se llega se encarne «a imagen y semejanza» del virtual del que se parte; razón por la cual todo proceso de actualización lo es ya siempre de «différenciation» (con una «c»). «Lo propio de lo virtual [dice Deleuze] es existir de tal forma que sólo se actualiza diferenciándose, que se ve forzado a diferenciarse, a crear sus líneas de diferenciación para actualizarse» $(B, 102)$. A contrario notaremos desde una perspectiva preformista que lo real siempre se parece a lo posible que realiza, de modo que el proceso de realización no cambia nada desde el punto de vista del concepto: lo real y lo posible son formalmente idénticos, el primero sólo tiene de más la existencia. En resumen, mientras que la identidad rige el proceso de realización, «la diferencia es lo primero en el proceso de actualización» $(B, 102)$.

Dicho esto - y volviendo a la frágil unidad que configura con el pensamientodiremos de la vida, en cuanto designa «lo no pensado en el pensamiento» $(Q F, 62)$, que constituye el horizonte último de lo que da que pensar, la «forma última de lo problemático» $(D R, 177)$. E, inversamente, de los problemas (con los que trata el pensamiento), que no son otra cosa que ramificaciones o propagaciones regionales de la vida — de ahí que el pensamiento nunca sea una cuestión puramente teórica, trata ya siempre de y con «problemas vitales»—. Ahora bien, para Deleuze, así como 
un problema es la marca de una diferencia, es decir, de un impensado que fuerza el pensamiento a pensar lo que aún no pensaba, asimismo se dirá de «la diferencia» que «es el único problema» $(D R, 84)$. La diferencia — recalca Deleuze- y no la contradicción. ¿Por qué? Porque la contradicción, según muestra nuestro autor, no es más que «el aspecto fenoménico y antropológico de la diferencia» (ID, 25), la manera de concebir la diferencia a través de su reflexión en una conciencia y para un sujeto (cfr. Bouaniche, p. 21). En otras palabras, diríase que la contradicción es lo que queda de la diferencia tras su crucifixión sobre los «cuatro brazos» de la representación (lo semejante, lo idéntico, lo opuesto y lo análogo), pues «siempre es en relación con una identidad concebida, con una analogía juzgada, con una oposición imaginada, con una similitud percibida que la diferencia llega a ser objeto de representación» (DR, 213-214; cfr. Canavera, 2015, p. 92 y ss.). En efecto, desde la perspectiva «única y huidiza» de la razón o del pensar representativo la diferencia siempre es vista como «algo maldito» y destinado a «expiar» $(D R, 389)$. Y aquí es precisamente donde entra en liza la contradicción, como instancia redentora por excelencia, que al estar enteramente al servicio del concepto y de sus exigencias representacionales, funciona como un instrumento de identificación y de dominio de la diferencia por reconducción forzosa de la misma hasta el «doble No» de la no-contradicción. Veamos el caso paradigmático de Hegel.

Para resolver el problema de la diferencia Hegel procede por identificación, pues considera que la única forma de domeñar la diferencia consiste en postular la identidad absolutamente abstracta de los términos en presencia; o, dicho de otra manera, en suponer que las relaciones que existen entre ellos les son interiores. En efecto, para que dos —o más— términos se excluyan mutuamente (el primer «no» como negación recíproca de los términos), es preciso que cada uno contenga en esencia al otro como «todo aquello que no es», y para que esto sea posible, que se postule la existencia de una identidad de fondo que los subsuma a ambos como partes necesarias e interdependientes de un mismo Uno-Todo, siendo esta previa subsunción de los contrarios lo que posibilita luego la resorción dialéctica (o síntesis reconciliadora) de su contradicción en una identidad de orden superior (el segundo «no» como negación de la negación y retorno al fundamento en tanto identidad sintética infinita). Por el contrario, cuando Deleuze afirma en un tono anti-hegeliano que «la diferencia no implica lo negativo, y no admite ser llevada hasta la contradicción más que en la medida en que se continúe subordinándola a lo idéntico», quiere dar a entender que la contradicción «es menos profunda y no más profunda que [la diferencia]» $(D R, 15,94)$. Y, correlativamente, que la conciencia, donde se refleja y concibe la diferencia como contradicción, es «siempre conciencia de un inferior en relación 
al superior, al cual se subordina o se "incorpora"» (NF, 60). Vale decir, conciencia de un inferior respecto del inconsciente, al que se dirigen —al menos, inicialmentelas diferencias. Por ello, sentencia Deleuze: «los conflictos, las oposiciones, las contradicciones nos han parecido efectos de superficie, epifenómenos de la conciencia»; y la Fenomenología de Hegel, una «epifenomenología» (DR, 397, 95).

Bien es cierto que la contradicción, la oposición y la negación, en tanto que conceptos formados para los menesteres de una lógica identitaria y de corte predicativo, son conceptos útiles para la intelección de lo real instituido (entendido como detención del impulso vital y reparto sedentario de los términos dados). Pero esto no quita que sean inservibles para aprehender la realidad haciéndose y la correspondiente producción de novedad o novación; vale decir, el surgimiento de la anomalía destituyente. En este sentido, si los conceptos de contradicción, negación y oposición testimonian una visión imprecisa de lo real, es ante todo porque no se puede proceder a fijar los términos dados en opositividades rígidas y estables («o bien... o bien...») sin que dichas oposiciones duales impliquen una abstracción de las diferencias reales; o, lo que es igual, sin que eclipsen el arcoíris de «matices» por el que, en realidad, los términos comunican los unos con los otros - pues tengamos presente que, en cuanto tal, «la diferencia no recorre [nunca] “todo el trayecto" hasta la oposición» (Hardt, pp. 86-87)—. Luego, si el pensar representativo (o dialéctico) se equivoca al creer que, recurriendo a «vagas síntesis de identificación de contrarios» $(A E, 82)$, puede «alcanzar lo real» (entendiendo aquí por «lo real» lo que se hace), es sencillamente porque — subraya Deleuze en tono bergsoniano- «jamás se alcanza lo concreto combinando la insuficiencia de un concepto con la insuficiencia de su opuesto, jamás se alcanza lo singular corrigiendo una generalidad por otra generalidad» $(B, 43)$.

En efecto, cuando el pensar representativo extrema LA Diferencia entiéndase: la pulsación inmanente de lo real y el vector de la novedad (DR, 102) hasta la contradicción, siempre acaba confundiendo: 1/ el concepto de diferencia (la Idea-problema como «entrelazamiento productivo de lo virtual» y «multiplicidad diferencial eternamente positiva») con una «diferencia simplemente conceptual», de manera que aquí «se comprende la diferencia en la identidad [conceptual]»; 2/ el concepto de repetición (el Eterno Retorno de lo Diferente) con una «diferencia sin concepto», definición que «continúa presuponiendo la identidad del concepto para lo que se repite; pero [que] en vez de inscribir la diferencia en el concepto, la pone fuera del concepto como diferencia numérica [de casos todos parecidos y contiguos]» (DR, 424), logrando así que la repetición se agote en una simple «reproducción de lo mismo», en un monótono eterno retorno de lo Mismo y a lo Mismo. De esa «confusión 
ruinosa» - y ruinosa, puntualiza Deleuze, tanto para una filosofía de la diferencia como para una filosofía de la repetición - se sigue una fatal consecuencia, a saber que diferencia y repetición, a ojos de la doxa representativa, son nociones que se excluyen mutuamente. Aquí diferir es un no repetir, un no hacer lo mismo; y repetir, un no diferir, un no innovar. Ahora bien, uno de los propósitos centrales de Deleuze es precisamente pensar, no sólo la diferencia y la repetición en su verdad, la primera como disfraz y la segunda como desplazamiento, sino también y sobre todo, en su complementariedad, ya que según nuestro autor no hay más repetición que de la diferencia. Para ello, es necesario cortocircuitar el pensar representativo y por ende neutralizar el soberano principio de identidad, en la medida en que «el primado de la identidad, cualquiera sea la forma en que ésta sea concebida, define el mundo de la representación» $(D R, 15)$.

$\mathrm{Al}$ hacer esto, lo primero que tenemos es que la relación entre diferencia y repetición, lejos de señalar un no-vínculo o una relación de exclusión mutua, se presenta, no sólo como un nexo de yuxtaposición («diferencia y repetición»), sino también y ante todo como una relación de co-pertenencia («diferencia es repetición»), en el sentido de que la diferencia, en cuanto «diferencia difiriendo», es el origen y el destino de la repetición, en tanto que «repetición diferencial»y «diferenciante» (o eterno retorno de lo absolutamente diferente). Luego, dado que nos situamos aquí en un terreno subrepresentativo donde ya no hay cabida para el concepto en general, el cual siempre hace las veces de un dispositivo que, «bajo la égida de lo idéntico, $[\ldots]$ disimula y cancela el "salir múltiple, en abanico" de la realidad» (Villani, 1999, p. 28) — es decir, de la(s) Idea(s)—, se coligen dos consecuencias cruciales: 1/ la diferencia no puede designar una opositividad rígida y estable de contradictorios, sino al contrario, señala la oposición viviente y móvil de términos heterogéneos; 2/ la repetición (o movimiento de la diferencia), lejos de designar una dialéctica de contrarios supeditada a una síntesis superior, reconciliadora y «presentificante», remite antes bien a un proceso de vice-dicción mediante el cual se abre una zona de indeterminación donde los términos, comunicando entre sí mediante «relaciones transversales (no jerarquizadas)» (DRL, 345), «mantienen su constante permutabilidad ("sea... sea..."), como si un término envolviera la potencialidad del otro a través de la distancia que los separa y los inscribe como heterogéneos» (Sibertin-Blanc, p. 38). Si resulta entonces imposible determinar aqui y abora (entiéndase: en presente) qué pertenece a quién, es porque toda repetición abre «un ámbito $a b$ que pertenece tanto a $a$ como a $b$ », pero «en el que $a$ y $b$ "se vuelven" indiscernibles»; lo que no significa, empero, que «uno se transforme en el otro, sino que algo pasa de uno a otro» $(Q F, 25,175)$. En este sentido, diremos de la 
repetición como movimiento de la diferencia que consiste en un devenir, esto es, un pasado-futuro virtual (Aiôn) cuya esencia — que es la de «tirar en los dos sentidos a la vez» (LS, 9)- hace que el devenir esté ya siempre esquivando el presente (Cronos) y sea asimismo irrepresentable. De ahí deriva a su vez una crucial consecuencia, a saber que el devenir constituye para el pensamiento la expresión de una paradoja (literalmente: de un «al lado» de la doxa) cuyo operador lógico central —nos dice Deleuze - es la disynnción inclusiva. Pero, ¿en qué consiste esta también llamada sintesis disyuntiva?

Tradicionalmente, la disyunción está cargada de negatividad. Se dice de ella que es exclusiva, en la medida en que designa una no-relación en la que cada término es la negación del otro o «niega lo que no es». En su acepción clásica, la disyunción remite, pues, a «un procedimiento de análisis que se limita a excluir los predicados de una cosa en virtud de la identidad de su concepto (uso negativo, limitativo o exclusivo de la disyunción)» (LS, 221). Pero, a ojos de Deleuze, cabe otro uso — esta vez afirmativo — de la misma. La disyunción (como «no-relación») sólo se convierte en una relación y por ende en una «verdadera síntesis» cuando hace de la divergencia y del descentramiento — que implica en sí misma- unos objetos de afirmación como tales. Así, pues, «en vez de que un cierto número de predicados queden excluidos de una cosa en virtud de la identidad de su concepto, cada "cosa" se abre al infinito de los predicados por los cuales pasa, al mismo tiempo que pierde su centro, es decir, su identidad como concepto o como yo. La exclusión de los predicados es sustituida por la comunicación de los acontecimientos [de los devenires]» $(L S, 222)$. En este sentido, se divisa que el uso afirmativo de la disyunción, lejos de designar una relación «dialéctica» de términos contradictorios que se realizaría bajo la égida de una identidad de fondo llamada a hacer las veces de condición de convergencia, señala antes bien una relación diferencial de términos heterogéneos, gracias a la cual cada término pasa en el otro «según un orden de implicación recíproco asimétrico, que no se resuelve ni en una equivalencia ni en una identidad de orden superior» (Zourabichvili, 2003, p. 79). De ahí que: 1/ la disyunción inclusiva (o síntesis disyuntiva) acabe confundiéndose con la afirmación de la distancia indescomponible a través de la cual los términos se relacionan como heterogéneos y preservan su constante permutabilidad; y que: 2/ adquiera un valor de defensa contra toda fijación identitaria en un pensamiento para el cual toda cosa (persona, objeto, lugar, materia, etc.) siempre va de la disyunción inclusiva (= devenir, acontecimiento) que la inaugura hasta la identificación exclusiva que la separa de lo que deviene. 


\section{DEL AFUERA DEL PENSAMIENTO AL PENSAMIENTO DEL AFUERA: PENSAR ES PROBLEMATIZAR, ES PRODUCIR EL SENTIDO}

De la afirmación de un mundo moviente, donde las identificaciones exclusivas se dicen de las disyunciones «ilimitativas» $(A E, 83)-\mathrm{y}$, en última instancia, donde «lo Uno se dice de lo múltiple», «el Ser del devenir» y «la necesidad del azar» (N, 4546) - se desprende una primera consecuencia capital en lo atinente a la actividad de pensar problemáticamente: ésta ya no tiene por objeto a lo real-actual (con sus puntos regulares, sus trazos rectilíneos y su segmentariedad dura); antes bien, debe atender a la mitad virtual de lo real y al cómo de su actualización (siempre regional). Ahora bien, para que los pliegues de lo real (en su devenir-línea) puedan convertirse en objeto de pensamiento, hace falta «poner entre paréntesis» (en sentido casi fenomenológico) el uso voluntario, inferior o empirico del pensar como reconocer; vale decir, «el ejercicio concordante de todas las facultades sobre un objeto que se supone [...] es el mismo objeto, que puede ser visto, tocado, recordado, imaginado, concebido» (DR, 206). Sin embargo, la suspensión de la concordia facultatum señala Deleuze - no depende de una «decisión premeditada» o de un acto de «buena voluntad»; antes bien, se origina en un movimiento involuntario, se produce a espaldas del pensador. ¿En qué consiste, pues, este movimiento que conlleva la puesta en jaque del mecanismo de reconocimiento, así como la neutralización del campo de los objetos reconocidos y/o de las significaciones explícitas? Señala ante todo el encuentro — «azaroso», «violento»y, en definitiva, «misosófico» (DR, 215)_ del pensamiento con un mínimo problemático: el signo. Elemento que, lejos de designar una esencia, una interioridad o un contenido descriptible, «implica en sí la heterogeneidad como relación» (PS, 32) y, de este modo, abre paso a lo problemático en el pensamiento, poniendo a este último en estado de exterioridad: el pensamiento se siente idiota al ser incapaz de pensar aquello — «real sin ser actual, ideal sin ser abstracto» (PS, 74) — que le ha salido al encuentro. No obstante, si «la génesis del acto de pensar [recalca Deleuze] siempre parte de los signos» (PS, 181), es porque en última instancia se da una insistencia (o persistencia) del signo por la cual - lo veremos de nuevo- el pensador supera la fase inicial de estupidez y de recelo — que provoca en él la violencia efractiva de «lo no-pensado»— y se ve asimismo forzado a convertir, en un desplazamiento clave del «afuera del pensamiento» al «pensamiento del afuera» (cfr. Canavera, 2015b), el no-sentido del «objeto encontrado» en la fuente de engendramiento del sentido mismo; lo cual, bien mirado, es otra manera de decir que «el sentido [siempre] es segundo y no primero» (Sauvagnargues, 2009, p. 178). Y si hablamos aquí de engendramiento es porque el sentido — que se halla implicado en el signo a modo de elemento distinto- 
oscuro — no está tanto para descifrar, como si de un «jeroglífico» se tratara (PS, 185), cuanto para producir $(L S, 98)^{3}$; y ello mediante un acto de problematización que constituye el auténtico acto de verdad del pensamiento.

Llegado este punto, es preciso señalar que no hay activación involuntaria del pensamiento por fulguración repentina del complejo «signo-sentido» en el espacio de la representación que no implique a su vez una verdadera destitución en cadena. Primero, de la quiebra del mundo de la representación se sigue el derrumbamiento de la (ilusión de) trascendencia que éste generaba, de modo que el fundamento («ontoteológico», como diría Heidegger), en cuanto punto-fuerte del «sistemamundo», deja paso a la «desfundamentación universal» (DR, 116); vale decir, al «vértigo filosófico» de la inmanencia (SPE, 164) donde comenzar —en el triple orden del ser, del saber y del hacer- significa repetirpara todas las veces, pues «todo lo que existe está en devenir, nada está dado "una vez por todas"» (Zourabichvili, 2004, p. 72). Segundo, a la destitución del «centro» divino sucede el resquebrajamiento del «círculo» del Yo o del ego especulativo — cuya «subsistencia, simplicidad e identidad expresan toda su semejanza con lo divino» (DR, 142)—, así como el derrumbe de la «esfera» cósmica o de la realidad exterior idéntica a sí misma; es decir: de la «forma individualizada de mundo» donde el yo paseaba su identidad «yendo de un objeto a otro según las leyes de un sistema determinado» (LS, 105). Kantianamente dicho, háblese de una doble destitución del Alma (como «horizonte interno» de todo acto noético-lingüístico) y del Mundo (como «horizonte externo» de todo estado de cosas) consecutiva a la muerte de Dios (como «horizonte último» y fuente común de ambos). «El mundo, el yo y Dios; esfera, círculo, centro»: ésa es, en pocas palabras, «la triple condición para no poder pensar el acontecimiento [de sentido]» (Foucault, p. 21). Una vez muerto Dios, el sujeto teórico — que tomaba la representación como criterio de lo que era y hacía del ser una realidad coextensiva de la representación, de la cual ésta había de contener la razón y medida—; en otros términos, esa «certidumbre esencial» — que de entrada se daba lo dado ya hecho- se desdibuja en provecho de una subjetividad que a contrario se caracteriza por «constituirse en lo dado»y, de este modo, «ser, en su esencia, práctica» (ES, 93, 115). He aquí el casi-sujeto deleuziano: «ante todo clínico, descifrador sensible y paciente de los regímenes de signos que produce la existencia, y según los cuales ella se produce» (Zourabichvili, 2003, p. 81). Asimismo, habrá de decirse de la mal

\footnotetext{
${ }^{3}$ Sobre el paso de la concepción hermenéutica del sentido como objeto de interpretación a la concepción experimentalista y funcionalista del sentido como objeto de producción y uso, véase Parmeggiani, 2003.
} 
llamada «realidad exterior» que pierde su (relativa) homogeneidad, neutralidad e impasibilidad para trocarse en un caosmos $(M M, 320)$, cuya beterogénesis hace que lo real, incluso actualizado, nunca esté completamente despojado de su estela de virtualidad; es decir, de aquello por lo que toda cosa, incluso en apariencia fijada, puede interpelar aún el ojo «metamorfoseante» (Villani, 1999, p. 28).

Luego de derrumbarse las Ideas trascendentales (Alma, Mundo y Dios) cuya función, para decirlo en clave kantiana, estribaba — subjetivamente - en «constituir hogares ideales fuera de la experiencia», hacia los cuales convergiesen los conceptos del entendimiento, y —objetivamente — en «"simbolizar" en relación con la materia de los fenómenos», de suerte que el entendimiento — que sólo podía legislar formalmente sobre los fenómenos- no se topase materialmente con una radical diversidad (FCK, 41-43); pues bien, luego de esta triple destitución no es sino la propia relación de la representación con el sujeto y el objeto la que, a su vez, e insalvablemente, salta por los aires, provocando de este modo la separación material $y$ formal del pensamiento y de lo que está por pensar. He aquí el momento en que «se desvanece tanto la identidad del objeto visto como la del sujeto vidente» (DR, 101) en provecho — dice Deleuze — de la visión no-subjetivada de un «SE» impersonal que, retrocediendo a un momento anterior al establecimiento del dualismo «Sujeto fijo/Objeto completo», se abre paso en el mundo vibrante y hormigueante —el único que, de hecho, merezca ser cualificado como «mundo sensible»— de las individuaciones dobles (o haecceidades); sopa a la vezpre-subjetiva y pre-objetiva donde debe ser localizada la génesis conjunta de un sujeto larvario, embrionario y paciente y de un objeto parcial, productivo y micrológico ${ }^{4}$. De esa destitución se sigue luego la del

\footnotetext{
${ }^{4}$ Este planteamiento — que acaba con el «privilegio otorgado al individuo constituido» (como diría Simondon) — implica, de hecho, una ruptura drástica con la modernidad: ya no se trata de saber cuáles son las condiciones requeridas para que dos o más términos previamente constituidos entablen relación, sino cómo se constituyen dos o más términos a partir de relaciones que se tejen previamente a su existencia. En este sentido se dirá del Objeto (como designación) y del Sujeto (como significación), ambos ya constituidos como términos exclusivos dispuestos el uno frente al otro sobre el plano molar (o macro) de la representación, que constituyen diferentes actualizaciones de una sola y misma virtualidad, el ya mencionado complejo signo-sentido; peculiar forma de unidad no conclusa (también llamada — lo hemos visto-Idea-problema) que los contiene inicialmente a ambos, en el plano molecular (o micro) de lo subrepresentativo, como sus distintos matices o grados virtuales, y que los hace comunicar originaria y disyuntivamente como las dos caras reversibles de un mismo Pliegue. Por ello —advierte Deleuze- «hemos de comprender que lo virtual, sin ser actual, es [...] aquello en lo que toda actualidad y toda realidad se distinguen, se comprenden y hunden sus raíces» (ID, 39).
} 
concepto en general como función mediadora que puenteaba y reconciliaba las dos series, subjetiva y objetiva, bajo la égida del principio de identidad: el concepto, como forma de la identidad desplegada en la representación, cede pues el puesto a la Idea-problema que, a modo de diferencia, virtualidad o multiplicidad pura, excluye con una mano a lo idéntico como condición de convergencia previa, pero no sin hacer comunicar transversalmente, con la otra, el sujeto larvario y el objeto parcial en un movimiento de tipo aberrante — con razón insiste Lapoujade en que el gesto deleuziano radica, como ya se mostrará más adelante, en eliminar la analítica de los conceptos para «enchufar» directamente la dialéctica (o génesis) de las Ideasproblemas sobre la estética (o disparación) de las intensidades, de los «bloques de sensaciones» (2014, p. 97). Finalmente, de la supresión del (uso representativo del) concepto se colige la destitución de la verdad, concebida tradicionalmente como asunto proposicional de adecuación de un concepto o de un enunciado a un estado de cosas, en provecho del sentido, entendido por su parte como un asunto extra-proposicional de creación problematizante, y ello en dos direcciones solidarias y complementarias: 1/ todo enunciado, «todo concepto remite a un problema, a unos problemas sin los cuales carecería de sentido» ( $Q F, 22) ; 2$ / todo problema a su vez remite a un posicionamiento vital del pensador — a un modo de habitar el mundo, si se quiere- sin el cual tendría una importancia, una relevancia y, en suma, un valor nulo.

Así es como «la prueba del sentido y del valor» (NF, 151) —entiéndase: la producción del sentido y la evaluación del sentido producido, la crítica y la clínica, en tanto que constituyen los dos aspectos indisociables e inherentes a la creación problematizante - está llamada, no a suprimir la cuestión lógica y proposicional de la verdad, sino a suplantarla en cuanto elemento último del pensamiento. Ahora — dice Deleuze- «el elemento del pensamiento es el sentido y el valor» (NF, 148), esto es, «el sentido de lo que se dice, la valoración del que habla» (ID, 177-178), y no lo verdadero, el cual consiste ya siempre en un «tenu pour vrai» y en un "généralement admis». Con Deleuze la vocación de la filosofía se sitúa ante todo en este «juego del no-sentido y del sentido»; vale decir, en un ámbito «previo» al de la lógica de la predicación y de la verdad-adecuación, como bien atestigua esta «paradoja coherente» según la cual «la fuente del más alto poder» de pensar ( = acto de problematizar, de abrir un horizonte nuevo de sentido) coincide aberrantemente con el momento de «la mayor impotencia del pensamiento» (= estupidez, sinsentido); pues, «ilo que lo fuerza [el pensamiento] a pensar [pregunta Deleuze] no es también la existencia de la estupidez, a saber, que él no piensa si no hay nada que lo fuerce?» $(D R, 407)$. Por ello, se dirá de la relación inclusiva e ilimitativa 
«sentido/sinsentido» que está destinada a convertirse aquí en la determinación superior o trascendental — que no trascendente_ del par empírico y cerrado «verdad/ falsedad». «El sentido [dice Deleuze] es la génesis o la producción de lo verdadero, y la verdad no es sino el resultado empírico del sentido» (DR, 236-237); lo cual se puede traducir también diciendo que todo concepto, todo enunciado siempre tiene la parte y el género de verdad que merece en función del sentido de lo que decimos y/o pensamos, así como del valor de aquello en lo que creemos (cfr. NF, 146; DR, 236). Pues bien, siempre podemos enunciar verdades, pero mientras el problema al que vienen referidas siga siendo un problema mal planteado, no será de extrañar que estas verdades continúen estando grávidas de estupidez y de bajeza. Henos aquí, en consecuencia, con lo que convendría caracterizar como una auténtica problematología en filiación directa con las filosofías nietzscheana y bergsoniana (cfr. Villani, 1999, p. 55): se trata de aprender — y no hay nada más difícil— a distinguir un buen problema de un falso problema; lo que a su vez conlleva saber «aplicar la prueba de lo verdadero y de lo falso a los problemas mismos, denunciar los falsos problemas, reconciliar verdad y creación en el nivel de los problemas» $(B, 11)$. De lo contrario, es decir, de creer que verdad y falsedad no conciernen más que a las soluciones, permanecemos atrapados en el viejo prejuicio, no sólo social — «pues la sociedad y el lenguaje [...] nos "dan" los problemas ya hechos, como sacados de las "carpetas administrativas de la ciudad"» $(B, 11)$ - o incluso infantil y escolar — «quien "da" el problema es el maestro, siendo la tarea del alumno descubrir su solución» $(B, 11)$ - , sino también bumanista, que nos hace creer que «todo pensamiento humano, y más todo pensamiento filosófico, se dirige siempre a los mismos problemas [...] fundamentales» (Strauss, p. 38), haciéndonos incurrir así en una suerte de esclavitud que merma nuestra verdadera libertad como pensadores: el «poder de decisión», «semidivino», «de constitución de los problemas mismos» $(B, 11)$.

Afirmar — como hace Deleuze— que «"el sentido de una proposición” no es más que el interés que suscita», a saber, «la novedad de una proposición» $(C, 207)$, es otra manera de decir, pues, que el sentido se confunde en última instancia con la vara de medir la verdad de lo que se dice y/o se cree. Así, pues, si las nociones de importancia, necesidad o interés son — para nuestro autor - infinitamente más decisivas que la noción de verdad, «no [es] porque ocupen su lugar, sino porque miden la verdad de lo que decimos» $(C, 207)$. Por todas estas razones, acaba concluyendo Deleuze que «la filosofía no consiste en saber, y [que] no es la verdad lo que inspira la filosofía, sino que son categorías como las de Interesante, Notable o Importante lo que determina el éxito o el fracaso» (QF, 84). Así las cosas, un 
problema sólo tendrá sentido, sólo será — local o regionalmente- interesante por cuanto implique cierta dosis de violencia y de novedad; vale decir, siempre y cuando permita desplazar una frontera en un campo del saber (como diría Foucault) y operar correlativamente un reparto original de las palabras y de las cosas, pues «el genio de una filosofía [escribe Deleuze] se mide, en primer lugar, por las nuevas distribuciones que impone a los seres y a los conceptos» $(L S, 15)$. Finalmente, de este complejo (o creación) problematizante, en la medida en que se identifica con la apertura de un horizonte nuevo de sentido, se dirá que tiene un valor — relativa y circunstancialmente - alto o noble, toda vez que potencie o intensifique la vida del pensador; bajo o vil, toda vez que la disminuya o la embote. Para Deleuze, que se inscribe en la estela nietzscheana, pensar no tiene otro cometido que «inventar nuevas posibilidades de vida» ( $N, 27)$; es decir, esencialmente, nuevas formas de sentir y de pensar, por cuanto vivir, para nosotros, nunca se hace sin pensar. Hay formas de vida y de pensamiento que exaltan y desarrollan la vida, y otras que la aprisionan y la rebajan.

Pues bien, si pensar problemáticamente significa indisociablemente producir el sentido $y$ evaluar lo alto o lo noble del sentido producido, ya que, «en filosofía [como ya advertía Deleuze], [el problema] y la crítica [del problema] son una misma cosa» (ES, 118), y si la producción (o génesis) del sentido, así como la evaluación del mismo, localizan su origen en un encuentro involuntario del pensamiento con el signo, pues «pensar siempre procede del afuera» $(F, 152)$, entonces se colige de ello que el acto de problematizar implica —al menos, en un primer momento- toda una maquinaria inconsciente. Razón por la cual «el pensamiento [escribe Deleuze] no piensa sino a partir de un inconsciente» (DR, 301); vale decir, a partir de un armazón de sintesis pasivas sobre las que se superponen luego las síntesis activas de conciencia $(D R, 121)$. En efecto, si el sentido y el valor constituyen el elemento del pensamiento, y si dicho elemento, a su vez, «no procede de un juicio o de una representación, sino de un proceso de producción [vital/deseante]»(Villani, 1999, p. 27), ajeno - por definición - a la voluntad del pensador, entonces bien hace falta convenir que «el sentido y el valor, las significaciones y las valoraciones hacen intervenir ante todo mecanismos inconscientes» (ID, 177-178). En otras palabras, el pensar problematizante es inseparable de una cierta exploración y conquista de esa «terra incognita jamás reconocida ni reconocible» $(D R, 210)$ que es el inconsciente; o, lo que es igual, la inmanencia, en tanto en cuanto «la inmanencia es el inconsciente mismo y la conquista del inconsciente» (SFP, 40). Exploración y conquista como veníamos diciendo- que, a su vez, y de alguna manera, obligan el pensador a invertir la consigna freudiana: «Allí donde el Ello estaba, ahí debo yo llegar como 
sujeto», con tal de que sea el Ello quien, de ahora en adelante, pueda advenir en el lugar del Yo. «El inconsciente [recalca Deleuze] ni lo tenéis, ni lo tendréis jamás, no es un "ello estaba" cuyo sitio debe ocupar el "Yo" (Je). Hay que invertir la fórmula freudiana. El inconsciente tenéis que producirlo» $(D, 90)$. Un inconsciente, sea dicho de una vez, antes bien maquínico que representacional; antes bien impersonal que psicológico; antes bien parecido a una «sustancia [ontológica] que hay que fabricar» que a un atributo antropológico ya dado a guisa de propiedad privada. Vale decir, un inconsciente mucho más parecido a una fábrica, repleta de «unidades de producción» (las máquinas deseantes en cuanto "productoras de realidad, y en realidad»), que a un teatro griego donde el deseo-carencia repetiría indefinidamente el drama edípico (cfr. AE, 32-36).

\section{UNA INEXPUGNABLE DOSIS DE EXPERIMENTALISMO: CUERPO-SIN-ÓRGANOS Y LÓGICA DE LA SENSACIÓN}

¿Qué significa explorar el inconsciente? Para Deleuze, no significa otra cosa — lo decíamos líneas atrás - que sumergir el pensamiento en las categorías de la vida. Ahora bien, ¿a qué remiten esas categorías? Designan antes que nada las capacidades, actitudes y posturas — por naturaleza heterogéneas - del cuerpo (esfuerzos, fatiga, espera, resistencias, etc.); heterogeneidad que convierte asimismo el cuerpo en la primera fuente de interrogaciones para el pensamiento. Henos aquí, de hecho, con la «fórmula de la inversión filosófica» (del platonismo): «dadme, pues, un cuerpo» (IT-C2, 251). Pero ese cuerpo del que nos habla Deleuze ya no es el obstáculo (externo) que separa al pensamiento de sí mismo y pervierte asimismo su naturaleza; señala antes bien aquello en lo que el pensamiento debe zambullirse para alcanzar lo impensado (= la vida). En este sentido, pensar problemáticamente no significa pensar por medio de un cuerpo ya constituido, sino pensar desde un cuerpo acerca del que no se sabe por anticipado de qué (afectos, relaciones de composición o descomposición, velocidades o lentitudes, etc.) es capaz. En efecto, «hablamos de la conciencia y de sus decretos, de la voluntad y de sus efectos, de los mil medios de mover el cuerpo y las pasiones, pero no sabemos ni siquiera lo que puede un cuerpo» (SFP, 27-28). En otras palabras, pensar problemáticamente es aprender lo que puede un cuerpo no pensante, pues «no es que el cuerpo piense, sino que obstinado, terco, él fuerza a pensar, y fuerza a pensar lo que escapa al pensamiento, la vida» (IT-C2, 251). Pensar, en definitiva, es experimentar en clave ética aquello a lo que la (visión) moral (del mundo) nos cierra el paso en virtud de su carácter prescriptivo («no hagas eso, no hagas aquello»), consecutivo al violento 
sometimiento que impone al cuerpo para con el alma y sus mandamientos. Por ello, el cuerpo (como superficie de experimentación) no puede designar ni el organismo (como régimen de totalización de los órganos), ni el cuerpo propio (en tanto que centro estructural y organizativo de la sensibilidad), ni tampoco la imagen figurada del mismo (que sería algo así como el último avatar del alma). Por el contrario, se trata de «un cuerpo afectivo, intenso, anarquista que tan sólo comporta zonas, polos, umbrales y gradientes. Una poderosa vitalidad no orgánica lo atraviesa» $(C C, 182)$. Y, ¿qué es lo que experimenta concretamente el pensador a través de ese cuerpo al que Deleuze, tomando prestada una fórmula de Artaud, llama «cuerpo-sin-órganos»? No se trata ni de percepciones (relativas a un estado de cosas específico) ni de afecciones (relativas a determinadas vivencias personales) ya codificadas, sean reales o posibles, sino de perceptos y/o afectos no subjetivados. Es decir, de puras intensidades, entendiendo por intensidad, no la materia en tanto que ya repartida en la extensión y ya recubierta por las cualidades correspondientes, sino algo así como el centro vivo de la materia, cuando no «la forma de la diferencia como razón de lo sensible» $(D R, 334)$ que preside justamente la génesis conjunta de la extensión y de las cualidades. Unas intensidades puras — como veníamos diciendo- que el pensador no puede evacuar por un escape motor, una acción o reacción psicológica; vale decir, un «desbordamiento sublime» que «nos impide disipar el afecto en energía motriz y nos obliga a convertirlo en pensamiento» (Sauvagnargues, 2009, p. 89).

Éstos son, pues, los dos aspectos fundamentales del pensamiento efectivo según Deleuze: así como pensar es problematizar a partir de un signo, de un «portador de problema» $(D R, 216)$ que, para ser pensado, arrastra necesariamente el pensador al «más grave proceso de despersonalización» $(C, 14)$, en el sentido en que sólo se puede pensar de otra manera deviniendo otro, es decir, perdiendo la posibilidad de decir «Yo» (cfr. Canavera, 2011); asimismo problematizar es experimentar a partir de una intensidad, esto es, de un «portasigno» (DR, 223) cuya fulguración — que cortocircuita subrepticiamente las vivencias ordinarias, así como los esquemas sensorio-motores llamados a hacer las veces de vector y soporte de la experiencia dóxica — sólo puede ser vivida al precio de una desorganización del cuerpo, y ello en el sentido de que tanto el Sujeto fijo como el Cuerpo constituido designan, a ojos de Deleuze, las dos vertientes de una misma hipostasis, resultante a su vez de un mismo proceso de subjetivación, que se caracteriza ante todo por «bloquear [el paso de] las intensidades separándolas de lo que pueden» (Villani, 1999, p. 81). No sin razón advertía ya nuestro autor que «lo que hay que evitar, ahora y siempre, es asignarle desde luego al [cuerpo] una organización que ha de llegarle sólo cuando 
el sujeto mismo llegue al espíritu, es decir, una organización que depende de los mismos principios que el propio sujeto» (ES, 96).

En resumidas cuentas, diríase que en Deleuze la lógica del sentido empieza forzosamente con una lógica de la sensación capaz de «captar fuerzas», siendo asimismo el pensamiento (entendido, no tanto como una facultad particular, sino como el devenir-activo de todas y cada una de las facultades subjetivas) a quien incumbe la tarea de hacer sensibles y pensables fuerzas que no lo son, de igual manera que «la música debe hacer sonoras fuerzas insonoras, y la pintura visibles fuerzas invisibles» (FB-LS, 63). Así, pues, se divisa que para «pensar de otro modo» (como diría Foucault) bay que sentir de otra manera (cuando no, romper con ese «ejercicio reglado y codificado del deseo "separado de lo que puede"» (Zourabichvili, 2003, p. 16) — que nos reconduce ya siempre hasta las formas estadística y comúnmente aceptadas de sentir y de percibir—, y ello, más profundamente, porque el deseo — que no es sino otro nombre de la vida, o la traducción mutatis mutandis de la Voluntad de Poder nietzscheana $(D, 103)$ — nunca es productor de realidad sin ser al tiempo «pathos» radical, «primitiva forma afectiva», «elemento genético y diferencial» de la sensibilidad (NF, 91, 121; Arnaud, 2008); en pocas palabras: poder de «abrirnos a lo inhumano y a lo sobrehumano» $(B, 25)$, «poder de ser afectado» $(F, 106)$ por todo aquello que escapa a la sabiduría y al equilibrio propiamente humanos). «La crítica [subraya Deleuze] no consiste en justificar, sino en sentir de otra manera: otra sensibilidad» (NF, 134). Henos aquí, pues, con el «privilegio de la sensibilidad [entiéndase: de la sensibilidad en cuanto desquiciada por la violencia efractiva del signo, es decir, por aquello que es insensible desde el punto de vista del reconocimiento, pero que — paradójicamente— no puede dejar de ser sentido desde un punto de vista sub-representativo] como origen» de la génesis del acto de pensar, del uso superior, trascendente $e^{5}$ o involuntario de las facultades pensantes; en pocas palabras: de la discordia facultatum. Ahora bien, ¿en qué consiste dicho privilegio? Atañe al hecho de que el signo, en tanto que designa el mínimo problemático a partir del cual se empieza a «engendrar "pensamiento" en el pensamiento» (DR, 227), fulgura ante todo en calidad de intensidad (= devenir, afecto, fuerza), de modo que sólo una sensibilidad liberada del molde del reconocimiento y de las categorías ordinarias — «humanas, demasiada humanas»— de percepción puede captarlo, vivirlo y dárselo luego a experimentar a las demás facultades pensantes.

\footnotetext{
${ }^{5}$ Véase DR, 220: «Trascendente no significa de ningún modo que la facultad se dirija a objetos que están fuera del mundo, sino, por el contrario, que capta en el mundo lo que la concierne exclusivamente y la hace nacer al mundo».
} 
En otras palabras, el privilegio de la sensibilidad consiste, bajo el asalto del signo $\mathrm{u}$ objeto encontrado — que es ante todo objeto sentido, sentiendum que «hace nacer la sensibilidad en el sentido» (DR, 216)—, en comunicar su violencia a las demás facultades, obligando así a cada una de ellas a llegar al límite, a elevarse a la más alta potencia, es decir, a no aprehender el objeto (el imaginandum para la imaginación, el memorándum para la memoria, el cogitandum para el pensamiento, etc.) que le corresponde si no es en la forma de un ir más allá del objeto reconocido. «En el camino que conduce a lo que queda por pensar [resume Deleuze] todo parte de la sensibilidad. De lo intensivo al pensamiento; siempre es por una intensidad que adviene el pensamiento» (DR, 223).

Henos aquí, pues, con el ejercicio superior de las facultades cuyas dos alas son, para Deleuze, la comprensión no-filosófica (por afectos y perceptos) y la comprensión propiamente filosófica (por conceptos); vale decir: la problematología y la pedagogía del concepto $(Q F, 22)$. La invención problematizante, por su parte, designa «la invención [que] le da el ser a lo que no era y hubiera podido no llegar jamás» (apud $B, 12$ ). A este fin, debe determinar cuáles habrán de ser los medios y términos mediante los cuales el problema será planteado; lo cual implica una triple operación que consiste en: 1/ hacer un corte - siempre parcial y provisorio, pero suficiente- en el flujo incesante e ilimitado de puntualidades (afectivas, perceptivas e intelectuales) con las que trata el pensamiento; 2/ ligar los datos seleccionados a raíz de este corte previo; 3/ extraer algo de sentido en base a la ligazón de los datos retenidos. «Instaurar un plano» sobre el caos - el cual «se caracteriza menos por la ausencia de determinaciones que por la velocidad infinita a la que éstas se esbozan y se desvanecen» ( $Q F, 26)$ - ése es, pues, el «primer momento», por definición, pre-filosófico o extra-conceptual, del pensamiento según Deleuze. Stricto sensu el plano problemático (también llamado - lo hemos visto- plano de inmanencia) remite efectivamente a un nivel distinto del concepto: un problema no es un concepto sino la meseta o superficie intuitiva sobre la cual éste se construye. Es, en definitiva, la instancia pre-filosófica, que sin llegar a ser trascendencia, excede no obstante el juego mismo de los conceptos que acoge en su seno, y para cuya instauración — que es deudora de «una lógica extrema y sin racionalidad» $(C C, 117)$ — debe el pensador «[recurrir] a medios escasamente confesables [...] del orden del sueño, de procesos patológicos, de experiencias esotéricas, de embriaguez o de excesos» (QF, 46). Llegado este punto es donde entra en liza la creación conceptual. Aquí no hay cabida para el uso representativo del concepto, es decir, para el concepto fijado, desprovisto de fuerza, que no cumple más que una función de denotación, útil como traza de una historia de las ideas y como rúbrica semántica en un diccionario. De lo que se trata es del concepto que 
aún se mueve, del concepto intensivo gracias al cual el pensamiento avanza; vale decir, del concepto que cumple una función de intercepción del sentido producido (cfr. Villani, 1999, p. 107). En resumidas cuentas, diríase que «la filosofía definida como creación de conceptos implica una presuposición que se diferencia de ella, y que no obstante le es inseparable. La filosofía es a la vez creación de concepto e instauración del plano. El concepto es el inicio de la filosofía, pero el plano es su instauración» $(Q F, 45)$. Razón por la cual «hacen falta ambas cosas, crear los conceptos e instaurar el plano, como son necesarias dos alas o dos aletas» (QF, 45).

\section{EL TIEMPO COMO INTENSIDAD PRODUCTIVA DE LOS CUERPOS}

Inversamente, diríase que no hay elevación de las facultades pensantes a la más alta potencia (entiéndase: ejercicio superior del pensamiento) sin un empirismo trascendental (cfr. Canavera, 2012) que —además de reevaluar la sensibilidad en su dimensión, no sólo sensorial, sino también pasional y tonal (Villani, 2013, p. 31)— preste una atención especial al tiempo. ¿Por qué? Porque el tiempo constituye ante todo el «dinamismo fundamental» $(E S, 100)$ por el cual lo dado en la experiencia, esto es, el flujo ilimitado de puntualidades afectivas, perceptivas e intelectuales, al que el espíritu aún no subjetivado es idéntico(ES, 93), puede rebasar su propio darse y alumbrar así una proto-subjetividad (el arriba aludido «SE» impersonal) que empieza a pensar silenciosamente en nosotros lo que nosotros no sabemos o no podemos pensar aún — recordemos que para Deleuze el sujeto se origina en esta contemplación contrayente que es el hábito, de modo que «lo que el sujeto es en su raíz es la síntesis del tiempo» (ES, 101) — . Pues si para pensar de otro modo — como se ha mostrado — hay que sentir de otra manera (y, más profundamente, desear de otra forma), resulta a su vez que para sentir (y desear) de otra manera hace falta devenir otro. De ahí se sigue una consecuencia crucial, a saber que el pensamiento (en cuanto devenir-activo de las facultades) mantiene - como bien supo mostrar Kant- una relación fundamental con el tiempo, y ello en tres sentidos complementarios. Primero, el tiempo sustituye a la idea clásica de una limitación del pensamiento por una exterioridad relativa (= extensión, espacio), que lo separaría de sí mismo, la idea de una exterioridad mucho más radical que lo trabaja desde adentro: el tiempo, dice Deleuze, «constituye el descubrimiento de la Diferencia, no ya como diferencia empírica entre dos determinaciones, sino Diferencia trascendental entre LA determinación [el pienso] y lo que ella determina [el soy], no ya como diferencia exterior que separa, sino Diferencia interna, y que relaciona a priori el ser y el pensamiento el uno con el otro» (DR 141). Segundo, 
el tiempo no es tanto «lo interior en nosotros» como «la interioridad en la cual somos, nos movemos, vivimos y cambiamos» (IT-C2, 115). Y tercero, el tiempo, cuya consistencia es puramente intensiva, no designa en última instancia otra cosa que la «intensidad de los cuerpos» (Zourabichvili, 2004, p. 82), es decir, la intensidad de la vida misma. De ahí que el tiempo, cual una transversal de las transversales o una «transversal universal» (Mengue, 1994, p. 128), constituya la relación intensiva (o intensa) que atraviesa, liga y hace funcionar conjuntamente esa «multiplicidad de planos heterogéneos de existencia» por la que se define la vida misma. En otras palabras, se dirá que «el tiempo es la diferencia de las diferencias» (Zourabichvili, Id., p. 80), o la diferencia interna que relaciona a las diferencias las unas con las otras. Diferencia interna o diferencia «en sí», como veníamos explicando, porque el tiempo es una «cosa» que no existe más que diferenciándose de sí misma y que no tiene otra identidad que la de diferir de sí misma, u otra naturaleza que la de «[no dividirse] sin cambiar de naturaleza» $(B, 41)$.

Ahora bien, ¿con qué género o clase de temporalidad suele tratar el pensar como representar o reconocer? Si tenemos en cuenta el hecho de que la representación, en su movimiento lógico y abstracto de someter las diferencias a la forma conceptual de la identidad, se caracteriza asimismo por el acto de traer algo a presencia, es decir, de presentificarlo, en una conciencia y para un sujeto, bajo la figuración de una imagen mental, entonces no es de extrañar que el marco temporal aquí privilegiado sea el del tiempo cronológico, sucesivo y unilineal propio del «presente englobante», del cual pasado y futuro no son más que dos dimensiones subalternas y fácilmente movilizables por el pensar representativo, respectivamente bajo la forma de la «observación-recuerdo» y de la «previsión» (DR, 121). Sin embargo, para Deleuze el presente englobante (o "presente que pasa») no es otra cosa que el reducto espacializado $(B, 36)$, es decir, la forma menos profunda de una temporalidad heterogénea, a-cronológica y multidimensional que se constituye en el entramado productivo de las síntesis pasivas del inconsciente (Habitus, Mnemosine, Tanatos $\left.{ }^{6}\right)$; lo cual se podría traducir también diciendo que

${ }^{6}$ Deleuze retoma aquí la tríada de síntesis kantianas (aprehensión, reproducción, reconocimiento), pero no sin redirigirlas a otro espíritu: las declina en su uso inmanente (o productivo), a la vez que las temporaliza, a imagen — mutatis mutandis— de las tres «ek-stasis» heideggerianas. Así, Habitus es la sintesis conectiva que constituye el tiempo como presente vivo por contracciónrepetición de instantes o de elementos sucesivos y mutuamente exteriores sobre un único y mismo plano. Mnemosine, por su parte, señala la sintesis conjuntiva que da lugar al pasado puro por contracción-repetición de planos o de niveles de pasado ilimitadamente implicados los unos 
«el tiempo es subjetivo, pero es la subjetividad de un sujeto pasivo» (DR, 120). Ahora bien, si hablamos aquí de un entramado productivo es porque dichas síntesis no son sintesis del tiempo sin ser simultáneamente sintesis de producción de lo real, de cuyo conjunto la vida — «el deseo y sus agenciamientos» (Mengue, 2003, p. 75) - es el nombre (AE, 33). Lo cual es otra manera de decir que, en Deleuze, temporalidad y productividad son nociones co-substanciales e incluso idénticas, pues «el tiempo es lo que se hace, e incluso aquello que hace que todo se haga» (Bergson, 1950, p. 3).

Ahora bien, en una «ontología evanescente» (como es la de Deleuze) donde: 1/ el tiempo es la diferencia de las diferencias; donde: 2 / la diferencia no se dice del ser (ya que se confunde con devenir) ni tampoco de lo ente (puesto que el devenir no va de un ente a otro, sino que se efectúa en el «entre»); y donde: $3 /$ el devenir - por definición plural — no designa jamás un devenir-uno o un devenir común, sino un «devenir-otro», no es de extrañar pues que de las tres síntesis constitutivas del tiempo heterogéneo y por ende del proceso de producción de lo real sea a la del porvenir en cuanto tal — esto es, al futuro inanticipable - a quien corresponda tener la última palabra. En efecto, ¿quién sino el futuro inanticipable (también llamado Eterno Retorno) puede constituir el horizonte temporal desde el cual se manifiesta la novedad, esta misma novedad que el futuro de la previsión retrotrae a lo antiguo, a lo ya conocido? Sin embargo, resulta que el futuro inanticipable (o Eterno Retorno) no es horizonte de la novedad sin constituir a su vez - ya

en los otros, o interiores los unos a los otros $(B, 61)$. En pocas palabras, diríase que Habitus engendra el tiempo como sucesión actual y Mnemosine como coexistencia virtual, de suerte que a cada instante el tiempo se desdobla en dos direcciones asimétricas, «en presente y pasado, presente que pasa y pasado que se conserva» (IT-C2, 115). Pero, a ojos de Deleuze, para quien dos tiempos no son suficientes para responder al «problema del pasaje» (NF, 72), es decir, a la sustitución de un presente por otro, hace falta una tercera síntesis del tiempo. He aquí, finalmente, Tanatos: es la sintesis disyuntiva que constituye el tiempo como futuro inanticipable por ramificación infinita y acoplamiento inédito de las dos líneas temporales heterogéneas, pero aberrantemente coexistentes, que son la actualidad del presente vivo y la virtualidad del pasado puro; «repetición regia» gracias al cual una dimensión virtual del pasado puro — como bien se puede experimentar en la fulguración del signo- irrumpe, diferenciándose de sí misma, en la actualidad del presente que pasa, suspende simultáneamente al presente-agente y al pasadocondición, al ser-presente y al Ser neutro, en provecho de una Diferencia interserial, que no pertenece ni a Habitus ni a Mnemosine, pero de la que ambos se dicen; en suma, de un «entredos-tiempos» $(Q F, 161)$ que produce el destello del acontecimiento y la correspondiente apertura de un nuevo campo de posibles. 
lo decíamos párrafos atrás - un horizonte tanatológico para todo sujeto bien constituido: pues, así como captar la novedad implica un devenir-otro, asimismo el devenir-otro supone dejar paso a otro yo que, surgiendo en mi lugar, me excluye a mí. El eterno retorno, como tercera síntesis del tiempo, no carece, empero, de coherencia; antes bien, posee una coherencia propia, pero ésta — como bien advierte Deleuze«no se plantea más que excluyendo mi propia coherencia, mi propia identidad, la del yo [moi], la del mundo y la de Dios» (DR, 148). En pocas palabras, diríase que el futuro como modo temporal original significa indisolublemente el Mundo (verídico) vuelto fábula, el Dios muerto, el Yo (Je) fisurado y el yo (moi) disuelto - "gran cañón del mundo, fisura del yo, desmembramiento divino» (LS, 224). Ésa es, pues, la «secreta coherencia» del eterno retorno: (el pensamiento de) lo intempestivo «me excluye en el instante mismo en que lo pienso» (Klossowski, p. 71), ya que me es imposible representarme en él.

\section{CONCLUSIÓN}

Habida cuenta de la importancia fundamental que cobra el tiempo en Deleuze, no es de sorprender que nuestro autor acabe haciendo suya la regla bergsoniana según la cual siempre hay que pensar, es decir, «plantear los problemas y resolverlos en función del tiempo más bien que del espacio» $(B, 28)$. Y si esto es así es porque toda creación, a ojos de un Deleuze naturalista que «ni siquiera deja subsistir la posibilidad de una cuestión "sobre [...] un ser colocado por encima de la naturaleza y el hombre"» (AE, 64), implica, no sólo el porvenir en cuanto tal como horizonte temporal de su manifestación, sino también y sobre todo cierta fe ateológica en dicho futuro, no siendo esta creencia a su vez otra cosa que el correlato del llamamiento inmanentista de nuestro autor a creer en el mundo (cfr. IT-C2, 230). He aquí, para concluir, la tarea propiamente ética que incumbe a la nueva figura del pensador como guerrero, a la nueva imagen del pensamiento como creación, así como al nuevo ejercicio del pensamiento como experimentalismo, pues "pensar es experimentar, es problematizar» $(F, 151)$. Así como el acto de problematizar (la lógica del sentido) implica una lucha contra la estupidez, y el de experimentar (la lógica de la sensación), una lucha contra el gregarismo, asimismo esa doble lucha contra la estupidez y el gregarismo - que constituyen las dos facetas, especulativa y práctica, del reconocimiento-implican a su vez una resistencia a la época y al presente en los que ambos se encarnan; en efecto, ¿qué son la estupidez y el gregarismo sino el indicio de «[esa] bajeza [que] no se separa del tiempo, es decir del transporte del presente, de esta actualidad en la que se encarna y se mueve» (NF, 151)? De 
ahí que pensar problemáticamente signifique «actuar contra el presente, y de este modo sobre el pasado, a favor (lo espero) de un porvenir» ( $Q F, 113)$.

\author{
Julien Canavera \\ Universitat de València \\ julien.canavera@uv.es \\ Liceo Francés Molière de Zaragoza \\ julien.canavera@mlfmonde.org
}

\title{
BIBLIOGRAFÍA
}

Althusser, L. (1974): Éléments d'autocritique, Paris: Hachette.

ARnAUD, F. (2008): «De la volonté comme pathos au désir comme production:

Schopenhauer, Nietzsche, Deleuze», en L'anti-Edipe de Deleuze et Guattari, Milan:

MétisPresses, pp. 27-36.

BADIOU, A. (1998): Court traité d'ontologie transitoire, Paris: Le Seuil.

Bergson, H. (1950): La pensée et le mouvant, Paris: PUF.

- (1962): L'évolution créatrice, Paris: PUF.

Bouaniche, A. (2007): Gilles Deleuze. Une introduction, Paris: Pocket.

CANAVERA, J. (2011): «Dé(cons)truire le sujet pour engendrer la pensée. Ce que philosopher

veut dire selon G. Deleuze», Éndoxa, no 28, pp. 227-256.

- (2012): «Hume en Deleuze: los primeros lineamientos del empirismo trascendental»,

Logos, vol. 45, pp. 123-144.

- (2015): «Gilles Deleuze: pensar problemáticamente», RODERIC, Universitat de València

(ed.). URL = http://roderic.uv.es/handle/10550/43533/. Consultado el 18-07-2015.

- (2015b): «Del "afuera del pensamiento" al "pensamiento del afuera": Deleuze entre

Blanchot y Foucault», Thémata, no 51, pp. 423-432.

- (2016): «El vitalismo de Gilles Deleuze», Daímon, no 66 (en prensa).

Chestov, L. (1967): Sur les confins de la vie. L'apothéose du déracinement, Paris: Flammarion.

Descombes, V. (1998): Lo mismo y lo otro, Madrid: Cátedra.

Deleuze, G. (1968): Spinoza et le problème de l'expression, Paris: Minuit = SPE.

- (1970): Lógica del sentido, Barcelona: Barral = LS.

- (1971): Nietzsche y la filosofía, Barcelona: Anagrama $=N F$.

- (1980): Diálogos (con C. Parnet), Valencia: Pre-Textos $=D$.

- (1987): El bergsonismo, Madrid: Cátedra $=B$.

- (1987): La imagen-tiempo. Estudios sobre cine 2, Barcelona: Paidós = IT-C2.

- (1987): Foucault, Barcelona: Paidós $=$ F.

- (1995): Conversaciones, Valencia: Pre-Textos $=C$.

- (1995): Prousty los signos, Barcelona: Anagrama $=P S$.

- (1996): Crítica y clínica, Barcelona: Anagrama $=C C$.

- (1996): Empirismo y subjetividad, Barcelona: Gedisa $=$ ES. 
- (1997): ¿Qué es la filosofía? (con F. Guattari), Barcelona: Anagrama = QF.

- (2000): Nietzsche, Madrid: Arena Libros $=N$.

- (2002): Diferencia y repetición, Buenos Aires: Amorrortu $=D R$.

- (2002): Francis Bacon. Lógica de la sensación, Madrid: Arena $=$ FB-LS.

- (2003): Mil Mesetas (con F. Guattari), Valencia: Pre-Textos = MM.

- (2004): El Anti Edipo (con F. Guattari), Barcelona: Paidós = AE.

- (2005): La isla desierta y otros textos, Valencia: Pre-Textos = ID.

- (2007): Dos regímenes de locos, Valencia: Pre-Textos $=$ DRL.

- (2007): La filosofía crítica de Kant, Madrid: Cátedra $=$ FCK.

- (2009): Spinoza: filosofía práctica, Barcelona: Tusquets = SFP.

FoucAult, M. (1995): Theatrum Philosophicum, Barcelona: Anagrama.

Hardt, M. (2004): Deleure. Un aprendiraje filosófico, Buenos Aires: Paidós.

Heidegger, M. (1988): Identidad y diferencia, Barcelona: Anthropos.

Husserl, E. (2001): Méditations cartésiennes, Paris: Vrin.

KANT, I. (1970): Crítica de la razón pura, Madrid: Clásicos Bergua.

KLOSSOwsKI, P. (1995): Nietzssche y el círculo vicioso, Buenos Aires: Altamira.

Lapoujade, D. (2014): Deleure, les mouvements aberrants, Paris: Minuit.

Marrati, P. (2004): Deleuze. Cinéma et philosophie, Paris: PUF.

MarTin, J.-C. (2005): La philosophie de Gilles Delenze, Paris: Payot \& Rivages.

Mengue, P. (1994): Gilles Deleuze ou le système du multiple, Paris: Kimé.

- (1996): Verdady mentira en sentido extramoral, Madrid: Tecnos.

- (2003): Deleure et la question de la démocratie, Paris: Kimé.

- (2007): La gaya ciencia, Buenos Aires: Gradifco.

- (2008): Más allá del bien y del mal, Madrid: Alianza.

PARdo, J.-L. (2006): La Metafísica, Valencia: Pre-Textos.

ParmegGiani, M. (2003), «Experimentalismo versus hermenéutica: G. Deleuze», Episteme NS, nº, pp. 127-149.

RODRíguez, R. (2006): Heidegger y la crisis de la época moderna, Madrid: Síntesis.

Sauvagnargues, A. (2004): Deleure. De l'animal à l'art, Paris: PUF.

- (2009): Deleuze. L'empirisme transcendantal, Paris: PUF.

Sibertin-Blanc, G. (2010): Deleuze y el Antiedipo, Buenos Aires: Nueva Visión.

STRAUSS, L. (1954): Droit naturel et histoire, Paris: Plon.

ViLLANi, A. (1999): La guêpe et l'orchidée. Essai sur Gilles Delenze, Paris: Belin.

- (2003): «Crise de la raison et image de la pensée chez Gilles Deleuze», Noesis, nº 5, pp. 203-216.

- (2013): Logique de Deleuze, Paris: Hermann.

ZourabichVILI, F. (2003): Le vocabulaire de Delenze, Paris: Ellipses.

- (2004): Deleure. Une philosophie de l'événement, Paris: PUF. 